\title{
APCOL: An example
}

LEE W. GREGG

Carnegie-Mellon University. Pittsburgh. Pennsvlvania 15213

A complete description of the APCOL programming system is printed in the Conference Proceedings in the session entitled "Programming Languages and Operating Systems." Lee Gregg discussed the APCOL system in detail under the title, "APCOL: A Programming System fur Computer-Controlled Psychology Laboratories." a paper coauthored by Allen L. Pinkus and Lee W. Gregg.

For this symposium. L. Gregg coded the Sternberg memory experiment in APCOL (see listing below).

Table 1

Sternberg Memory Experiment (1966) Coded in APCOL

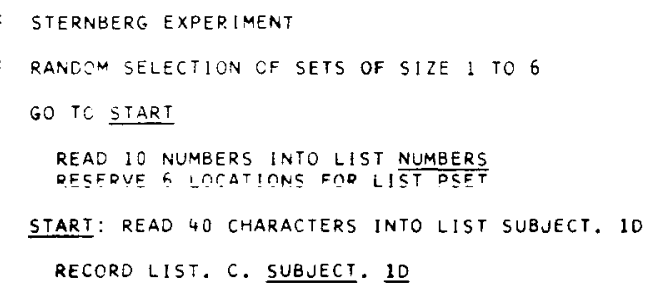

Table 1 (Cont.)



REFERENCE

Sternberg. S. High-speed scanning in human memory. Science, $1966,153,652-654$. 